\title{
The STICH trial: Misguided conclusions
}

\author{
Gerald D. Buckberg, MD, ${ }^{\mathrm{a}}$ and Constantine L. Athanasuleas, $\mathrm{MD}^{\mathrm{b}}$
}

Supplemental material is available online.

This editorial summarizes a counterpoint American Association for Thoracic Surgery debate opinion after the recent Surgical Treatment for Ischemic Heart Failure (STICH) trial published in The New England Journal of Medicine (NEJM). ${ }^{1}$ That article may potentially alter treatment of congestive heart failure (CHF) after ischemic dilated cardiomyopathy following myocardial infarction because the authors conclude that adding surgical ventricular reconstruction to reduce ventricular volume to coronary artery bypass grafting (CABG) does not improve symptoms or exercise tolerance and fails to lower death rate or cardiac rehospitalization.

The original study examined the role of surgical ventricular reconstruction or "surgical ventricular restoration" (SVR) in the dilated ventricles of patients with CHF with regional scar after anterior myocardial infarction (Figure 1). The adverse effects of dilatation are codified by White and associates $^{2}$ (Figure 2, $A$ ), who showed that increased ventricular volume rather than altered ejection fraction became the principal surrogate for mortality.

Dor $^{3}$ showed that the SVR procedure excludes the underlying culprit scar that causes stretch of compensating remote muscle, identified similar regional noncontraction from either aneurysm or akinetic segments that received thrombolysis or angioplasty, and demonstrated that rebuilding left ventricular (LV) size and shape toward normal improves cardiac efficiency by restoring remote muscle function. The keynote finding of similarly absent function in aneurysm without reperfusion (in which the thinned scar collapses during venting) and akinesia after reperfusion (in which the thick myocardium with inner shell scar is covered by normal anterior myocardium that does not collapse during venting) introduced a "new SVR target" and initiates " a learning curve" for procedure application.

SVR after CABG is based on an international database registry of more than 5000 patients. $^{3-5}$ This database

From the University of California Los Angeles, ${ }^{a}$ Los Angeles, Calif, and the University of Alabama, ${ }^{\text {b }}$ Birmingham, Ala.

Received for publication May 28, 2009; revisions received June 12, 2009; accepted for publication July 7, 2009.

Address for reprints: Gerald D. Buckberg, MD, David Geffen School of Medicine at UCLA, Division of Cardiothoracic Surgery 62-258 CHS, 10833 Le Conte Ave, Los Angeles, CA 90095 (E-mail: gbuckberg@mednet.ucla.edu).

J Thorac Cardiovasc Surg 2009; 138:1060-4

$0022-5223 / \$ 36.00$

Copyright (c) 2009 by The American Association for Thoracic Surgery doi:10.1016/j.jtcvs.2009.07.015
(Figure 3) demonstrates favorable survival compared with CHF natural history studies ${ }^{6}$ and a CABG patient cohort whose abnormal ejection fraction and class III/IV New York Heart Association classification matched the RESTORE (Reconstructive Endoventricular Surgery, returning Torsion Original Radius Elliptical Shape) group registry cohort $^{4,7}$ in National Heart, Lung, and Blood Institute STICH grant application and the worldwide SVR registry. A prospective randomized trial was designed for "evidence based medicine" confirmation.

The 490 STICH trial patients requiring SVR did not show survival or rehospitalization differences compared with the greater than 5000 patient registry SVR database, thereby raising this question: IS SVR an improper concept or did the STICH trial have improper execution? The solution to this question will determine whether STICH results provide credible data that guide the treatment of patients with CHF. We conclude that it did not, and this editorial supports this deduction with trial evidence, reports casualties of the STICH findings, poses new questions requiring answers, and outlines future STICH report meaningful data analysis that may properly respond to grant questions.

\section{STICH TRIAL BACKGROUND AND EXECUTION}

Initial planning required exclusion of the culprit scar with nonviable regions confirmed by nuclear scans to avoid confusion of hibernation within viable muscle. Two new steps were required. First, participating cardiologists had to measure volume in trial entry patients with ejection fractions of less than $35 \%$, since differing volumes may have a similar ejection fraction (Figure 2, B). Second, surgeons had to incise the normal epicardium over underlying thick-walled scar and reduce volume 30\% below baseline levels. This amount of volume reduction was selected because approximately $40 \%$ volume reduction (Table 1 ) was needed for clinical improvement in prior SVR reports of more than 5000 patients. STICH measured volume in only 161 of 490 SVR patients and concluded that SVR is not better than CABG. Unfortunately, no evaluation could be made in $66 \%$ of SVR patients whose volume was not measured. CHF severity reached grade III/IV (New York Heart Association) in only $49 \%$ of patients in the STICH cohort versus approximately $67 \%$ in SVR registry reports, ${ }^{4}$ but post hoc analysis can make such data-based comparisons.

Two entry criteria existed in the original protocol. First, LV stroke volume index must be beyond $60 \mathrm{~mL} / \mathrm{m}^{2}$. The background volume requisite for surgical intervention stemmed from the report by White and associates ${ }^{2}$ and 


\section{Abbreviations and Acronyms \\ CABG = coronary artery bypass grafting \\ $\mathrm{CHF}=$ congestive heart failure \\ CMR = cardiac magnetic resonance \\ $\mathrm{LV}=$ left ventricle (ventricular) \\ NEJM = The New England Journal of Medicine \\ RESTORE $=$ Reconstructive Endoventricular \\ Surgery, returning Torsion \\ Original Radius Elliptical Shape \\ STICH = Surgical Treatment for Ischemic \\ Heart Failure \\ SVR = surgical ventricular restoration}

from experience in aortic and mitral valve disease, where progressive remodeling is not prevented if valve interventions are made after end-systolic volume index (ESVI) exceeds $60 \mathrm{~mL} / \mathrm{m}^{2}$ (Figure E1). ${ }^{18}$ Second, documentation of greater than $35 \%$ akinesia from anterior wall necrosis was necessary to show that the culprit scar caused remote muscle dilatation that exceeded the $60 \mathrm{~mL} / \mathrm{m}^{2}$ entry point.

These established primary objectives became altered in 2006 (http://clinicaltrials.gov/show/NCT00023595). Such protocol deviation from approved entry criteria is possible by executive decision by the principal investigator, can only occur with approval of the National Institutes of Health grant administration officer, and does not require approval from the other trial participants. Investigational review board notification of this change to other trial participants is their responsibility. The new primary objective included "documented LV anterior wall dysfunction" if necrosis and volume measurements were absent. Moreover, 13\% of patients had not had a myocardial infarction.

These primary goal changes introduced wall motion disorders that may occur without necrosis after acute ischemia or hibernation or may follow scar. Ischemic muscle without scar may recover after $\mathrm{CABG},{ }^{19}$ but this cannot happen if gadolinium magnetic resonance studies show greater than $50 \%$ of muscle is scarred. ${ }^{20} \mathrm{SVR}$ has never been recommended in ventricles without scar, and applying SVR in hibernating myocardium was not reported by Dor $^{3}$ in more than 1000 patients or the 1198 RESTORE patient cohort, in which all patients displayed electrocardiographic and imaging evidence of large akinetic or dyskinetic scar with greater than $60 \mathrm{~mL} / \mathrm{m}^{2}$ ESVI measurements.

Echocardiography was used to measure LV volume in the NEJM report but was evaluated in only $38 \%$ of STICH patients (212/490 CABG patients and 161/490 CABG and SVR patients). Application of this echo-measuring technique contradicts original and present protocol requirements (Supplemental Data 1), where echocardiography is accepted during

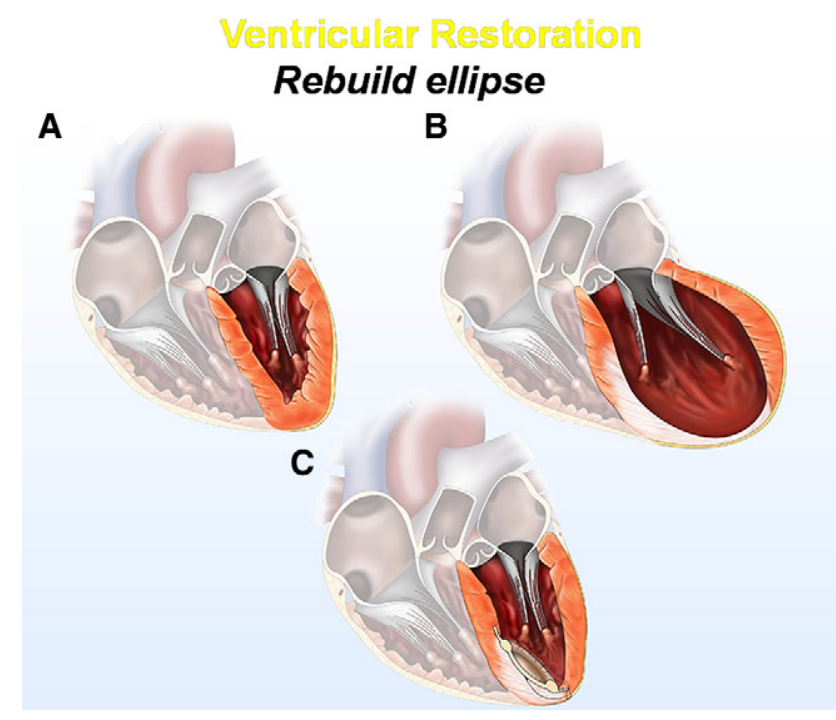

FIGURE 1. Changes in LV size and shape after SVR. The elliptical normal form (A) becomes spherical after anterior septal infarction (B). Size and shape are returned toward a more normal elliptical configuration by placing a patch to exclude the scar and returning nonscarred remote muscle back to its conical form (C). Reprinted with permission from Buckberg G. Ventricular Structure and surgical history. Heart Failure Rev. 2005;9:255-68.

screening to measure ejection fraction, but $100 \%$ of consenting patients required cardiac magnetic resonance (CMR) or gated single photon emission computed tomography scans to measure volume before and after SVR or CABG. Grant planning excluded 2-dimensional echocardiographic measurement of volume because regional asynergy in ischemic disease makes it unreliable for volume measurement, ${ }^{21}$ but this limitation becomes offset by CMR 3-dimensional volume analysis.

LV volume was reduced by $19 \%$ in SVR patients to reach a volume end point that reflects an inadequate repair as determined by the Surgery Therapy Committee, whose "acceptable STICH procedure" guideline required a 30\% ESVI decrease at 4-month CMR measurement (Supplemental Data 2). Failure to achieve benchmark volume reduction differs markedly from SVR values shown in Table 1, averaging $40 \%$ reduction and ranging between $30 \%$ and $58 \%$. Consequently, the STICH SVR procedure may have reflected a small LV plication or limited intracavitary reconstruction.

Alteration of primary aim changes was suggested in a 2005 trial editorial, "To STICH or not to STICH: We Know the Answer, but Do We Understand the Question,',22 which reached conclusions about questions the grant was assigned to test. Publication of this report led to an immediate editorial in this Journal, " Questions and Answers About the STICH Trial: A Different Perspective," ${ }^{, 3}$ in which answers to original grant application goals were requested.

\section{STICH FLAWS}

The credibility of the STICH trial is questioned by flaws addressed in trial background above and execution sections by 
Relative Risk for Death Post MI

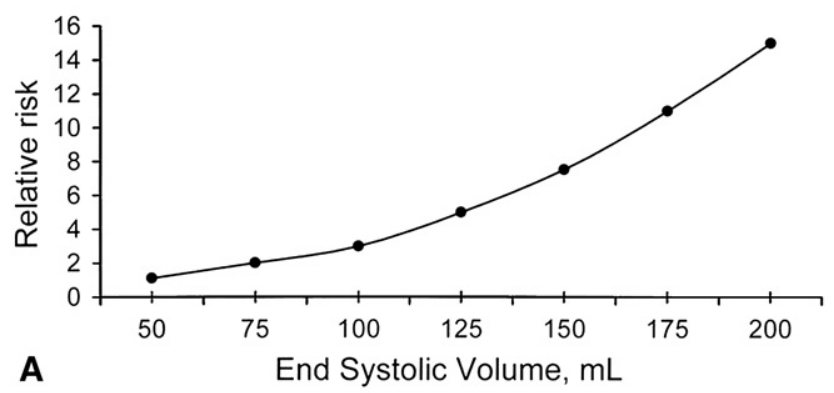

LVESV vs. Ejection Fraction

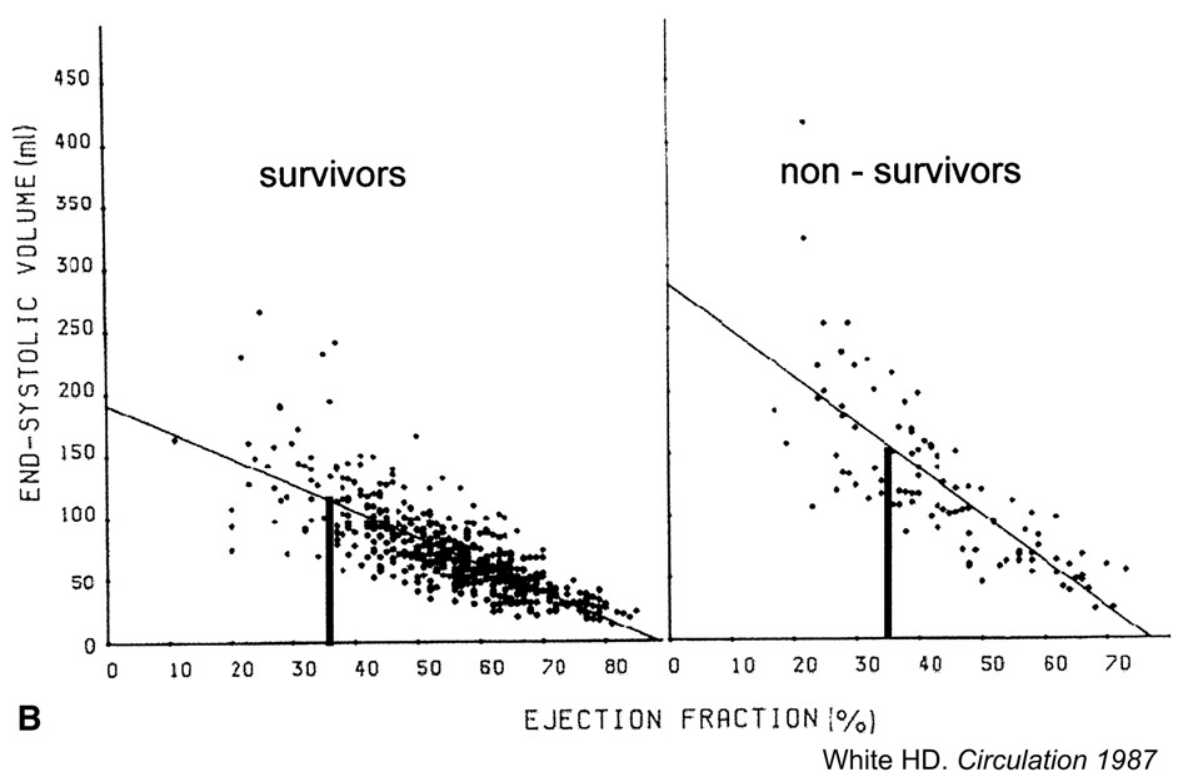

FIGURE 2. A, Relationship between LV end-systolic volume and mortality. Note (1) that volume is in milliliters, not milliliters per square meter, so that the LV end-systolic volume index would be twice this number if patient size were $2 \mathrm{~m}^{2}$ and (2) that volume increase is a surrogate for increased mortality. ${ }^{2} \mathrm{~B}$, Comparison of prognosis in survivors and nonsurvivors in relationship to ejection fraction (solid line is at $35 \%$ ) and LV end-systolic volume in milliliters. Note that lower LV endsystolic volume at $35 \%$ ejection fraction is associated with reduced mortality in survivors compared with increased mortality in nonsurvivors when LV end-systolic volume is higher at $35 \%$ ejection fraction. ${ }^{2} M I$, Myocardial infarction; $L V E S V$, left ventricular end-systolic volume. Reprinted with permission. ${ }^{2}$

those listed below. First, all patients needed to have akinesia, yet only $50 \%$ displayed this finding. Second, akinesia developed from regional necrosis of $35 \%$ of muscle, yet the report fails to document this scar finding (Supplemental Data 3). Third, CMR quantification of ventricular volume is needed in all patients before and after SVR. Instead, 19\% underwent an invalid echocardiographic measurement, despite pretrial contact showing CMR measurement capacity in all initial 50 trial centers (Supplemental Data 4). Fourth, 100\% required CMR volume measurement for trial entry, yet only $38 \%$ (CABG and CABG plus SVR) had any form of volume measurement. Fifth, SVR is indicated only if ESVI is beyond 60 $\mathrm{mL} / \mathrm{m}^{2}$, yet volume measurements for SVR or CABG without SVR candidates were not reported. Sixth, 30\% reduction of ESVI at 4 months by CMR study is required for acceptable SVR procedure, but ESVI was lowered only $19 \%$ in the $33 \%$ of patients to demonstrate an inadequate end point. Sev- enth, the original trial included 50 centers, averaging approximately 10 cases per center. Actually, 96 centers were used, averaging approximately 5 procedures per center, so that Surgical Therapy Committee outcome validation during accreditation becomes a vital earmark before trial enrollment. Its initial meeting outlined 10 cases per center and 5 per surgeon, demonstrating the required $30 \%$ volume reduction. Instead, no specification is shown that pretrial ESVI reduction fulfilled trial eligibility criteria.

\section{EVIDENCE BASED MEDICINE AND ROLE OF EXPERIENCE}

The hallmark of technical competence after a surgical procedure requires reaching goals that comply with yardsticks of procedural success. For SVR, favorable clinical results followed approximately $40 \%$ volume reduction below control levels in more than 1500 cases in 12 worldwide centers 


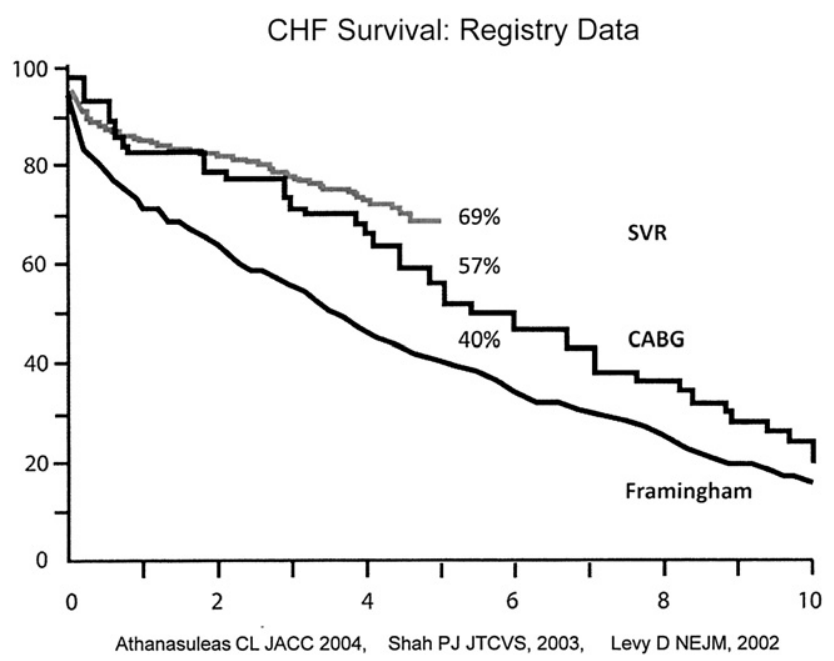

FIGURE 3. Overall hospital and late follow up mortality in patients with congestive heart failure $(C H F)$ after medical therapy, as reported by the Framingham analysis, ${ }^{6}$ coronary revascularization (reprinted with permission), ${ }^{7}$ and surgical ventricular restoration (reprinted with permission). ${ }^{4}$

(Table 1). In contrast, STICH reduced ventricular volume $19 \%$ in 161 patients, and 96 centers were required to achieve this end point. No volume studies occurred in $66 \%$ of patients and an invalid echo-based monitoring method was used in the others. These limitations did not prevent STICH end point interpretation that SVR should be abandoned because CABG achieved similar results. The "evidence based medicine" analysis used to justify this conclusion does not consider how results relate to evaluation of nonapproved volume outcomes in only $33 \%$ of patients or how experience influences end point validity.

The 2005 editorial by one of us $^{23}$ (G.D.B.) suggested potentially inaccurate conclusions after volume reduction by comparing STICH to the 1976 Veterans Administration Hospital CABG study $^{24}$ of ischemic coronary artery disease revascularization versus medical therapy. The 300 surgically treated patients in 12 centers had $6 \%$ mortality (range $3 \%-12 \%$ ) and closed conduits related to individual center experience. This contrasts with $1 \%$ mortality and superb graft patency in a 1978 report of 1000 patients from the Cleveland Clinic $^{25}$ to demonstrate how experience based observations influence subsequent management. STICH trial inexperience potential may relate to the learning curve of adequately reducing ventricular volume while doing a new procedure when only about 5 cases per center are performed. Misguided results may camouflage proper outcome analysis and impair correct treatment in the same way that coronary revascularization can be considered unsuccessful when only internal thoracic artery grafting is done without addressing a stenotic right coronary artery, or concluding that antihypertensive drugs are ineffective in studies that used inadequate medication dosages.

We believe that differences between STICH outcomes and worldwide SVR data displaying greater volume reduc-
TABLE 1. Left ventricular end-systolic volumes before and after surgical ventricular restoration

\begin{tabular}{|c|c|c|c|c|}
\hline \multirow[b]{2}{*}{ Author(s) (year) } & \multirow[b]{2}{*}{ No. of patients } & \multicolumn{3}{|c|}{$\operatorname{ESVI}\left(\mathbf{m L} / \mathbf{m}^{2}\right)$} \\
\hline & & Preop. & Postop. & Reduction (\%) \\
\hline \multicolumn{5}{|l|}{ Di Donato et $\mathrm{al}^{8}$ (2009) } \\
\hline Type 1 & 56 & 83 & 35 & $48(58)$ \\
\hline Type 2 & 55 & 87 & 39 & $48(55)$ \\
\hline Type 3 & 67 & 96 & 57 & $39(41)$ \\
\hline Suma et $\mathrm{al}^{9}$ (2009) & 76 & 123 & 74 & $49(40)$ \\
\hline Dor et $\mathrm{al}^{10}(2008)$ & 104 & 93 & 51 & $42(45)$ \\
\hline Menicanti et $\mathrm{al}^{11}$ (2007) & 301 & $173^{*}$ & $100 *$ & $73 *(42)$ \\
\hline O’Neill et al ${ }^{12}$ (2006) & 135 & 120 & 77 & $43(36)$ \\
\hline Adams et $\mathrm{al}^{13}$ (2006) & 8 & 92 & 59 & $33(36)$ \\
\hline Schreuder et $\mathrm{al}^{14}$ (2005) & 9 & 92 & 45 & $47(51)$ \\
\hline Tulner et $\mathrm{al}^{15}$ (2006) & 21 & $186^{*}$ & $101^{*}$ & $85 *(46)$ \\
\hline Yamaguchi et al ${ }^{16}(2005)$ & 20 & 137 & 65 & $72(53)$ \\
\hline $\begin{array}{l}\text { Mickleborough et al }{ }^{17} \\
\text { (2004) }\end{array}$ & 41 & 97 & 65 & $32(33)$ \\
\hline $\begin{array}{l}\text { Athanasuleas et al } \\
\left.\text { (RESTORE group }{ }^{4}\right) \\
(2004)\end{array}$ & 671 & 80.4 & 56.6 & $24(30)$ \\
\hline $\begin{array}{c}\text { Jones et al (STICH } \\
\left.\operatorname{group}^{1}\right)(2009)\end{array}$ & 161 & 83 & 67 & $16(19)$ \\
\hline
\end{tabular}

Data compiled by Hisayoshi Suma, MD. ESVI, End-systolic volume index. *End-systolic volume $(\mathrm{mL})$, not indexed.

tion indicate that the wrong operation, using the wrong volume measurement monitors, was done on the wrong patients and resulted in the wrong conclusions. This outcome deprives cardiologists of understanding the potential role of volume reduction to treat $\mathrm{CHF}$ from ischemic dilated cardiomyopathy and demonstrates that the goals of evidence based medicine were not achieved.

\section{CASUALTIES OF STICH OUTCOMES}

The first casualty of this report may be the increasing CHF population with dilated hearts, which makes up approximately half of the CHF population, ${ }^{26}$ whereby misguided conclusions may hamper proper treatment decisions. STICH end points do not relate to the SVR procedure that requires properly measuring necrosis and accurate ventricular volume before reducing volume more than $30 \%$ below preoperative levels.

Second, STICH may adversely affect cardiac surgery evolution and nontransplant heart failure surgery by limiting development of SVR, a unifying geometric treatment of dilated cardiomyopathy from ischemic and nonischemic causes. Moreover, SVR may link with LV assist devices to introduce a "bridge to restoration" approach and ultimately may create a surgical scaffold that marries this macroscopic approach with cell therapy. The flawed database underlying STICH findings may also limit future government interest in funding other surgical trials.

The third casualty is scientific integrity, because measuring volume rather than ejection fraction as the natural 
surrogate for development of adverse clinical findings in dilated hearts becomes impaired by STICH findings.

The fourth casualty may be health care cost of CHF treatment, which may exceed \$1 trillion per year in 2030 (Figure E2). ${ }^{27}$

\section{STICH CONCLUSIONS AND QUESTIONS TO BE ANSWERED}

The following debate questions still require a proper response. First, is ESVI measurement important in evaluating and treating dilated cardiomyopathy? Second, why were incorrect volume measurements used? Third, does CABG treatment lead to improved function in scarred muscle? CABG is used in the non-SVR group that does not exclude the scarred segment. Fourth, where are viability measurements showing $35 \%$ regional necrosis in all included patients? Fifth, is there confirmed validation of center-surgeon eligibility showing greater than $30 \%$ volume reduction to comply with Surgical Therapy Committee guidelines? Sixth, did STICH study ischemia (with or without hibernation) or postmyocardial infarction anterior scar? Seventh, why were the primary objectives changed? Eighth, do STICH conclusions invalidate the extensive SVR patient registry database?

\section{STICH CONCLUSIONS AND MEANINGFUL END POINTS}

This analysis of STICH report flaws and conclusions suggests the trial should retract the NEJM report or reanalyze data to achieve meaningful results. The target goal must (1) exclude all patients with invalid echocardiographic volume measurements, (2) include only patients in whom regional nonviability of greater than $35 \%$ akinesia is documented by nuclear medicine scans, (3) quantify all patients with greater than $30 \%$ volume reduction by CMR study, and (4) report only patients with "acceptable" volume reduction by CMR at 4 months. The STICH trial must address each of these questions because misguided STICH conclusions contradict the role of augmented ventricular volume as the surrogate for the natural history of increasing morbidity and mortality in dilated hearts. ${ }^{2,18}$ Without this action, the STICH trial conclusions simply show that statisticians can defy nature from a flawed database.

\section{References}

1. Jones RH, Velazquez EJ, Michler RE, Sopko G, Oh JK, O'Connor CM, et al. Coronary bypass surgery with or without surgical ventricular reconstruction. $\mathrm{N} \mathrm{Engl} \mathrm{J}$ Med. 2009;360:1705-17.

2. White HD, Norris RM, Brown MA, Brandt PW, Whitlock RM, Wild CJ. Left ventricular end-systolic volume as the major determinant of survival after recovery from myocardial infarction. Circulation. 1987;76:44-51.

3. Dor V. Left ventricular reconstruction: the aim and the reality after twenty years. J Thorac Cardiovasc Surg. 2004;128:17-20.

4. Athanasuleas CL, Buckberg GD, Stanley AW, Siler W, Dor V, Di Donato M, et al., for the RESTORE group. Surgical ventricular restoration in the treatment of congestive heart failure due to post-infarction ventricular dilation. $J$ Am Coll Cardiol. 2004;44:1439-45.
5. Menicanti L, Di Donato M. The Dor procedure: what has changed after fifteen years of clinical practice? J Thorac Cardiovasc Surg. 2002;124:886-90.

6. Levy D, Kenchaiah S, Larson MG, Benjamin EJ, Kupka MJ, Ho KK, et al. Longterm trends in the incidence of and survival with heart failure. N Engl J Med. 2002; 347:1397-402.

7. Shah PJ, Hare DL, Raman JS, Gordon I, Chan RK, Horowitz JD, et al. Survival after myocardial revascularization for ischemic cardiomyopathy: a prospective ten-year follow-up study. J Thorac Cardiovasc Surg. 2003;126:1320-7.

8. Di Donato M, Castelvecchio S, Kukulski T, Bussadori C, Giacomazzi F, Frigiola A, et al. Surgical ventricular restoration: left ventricular shape influence on cardiac function, clinical status, and survival. Ann Thorac Surg. 2009;87:455-62.

9. Suma H, Tanabe H, Uejima T, Isomura T, Horii T. Surgical ventricular restoration combined with mitral valve procedure for end stage ischemic cardiomyopathy. Eur J Cardiothorac Surg. 2009 (in press).

10. Dor V, Civaia F, Alexandrescu C, Montiglio F. The post-myocardial infarction scarred ventricle and congestive heart failure: the preeminence of magnetic resonance imaging for preoperative, intraoperative, and postoperative assessment. $J$ Thorac Cardiovasc Surg. 2008;136:1405-12.

11. Menicanti L, Castelvecchio S, Ranucci M, Frigiola A, Santambrogio C, de Vincentiis C, et al. Surgical therapy for ischemic heart failure: single-center experience with surgical anterior ventricular restoration. J Thorac Cardiovasc Surg. 2007; 134:433-41.

12. O'Neill JO, Starling RC, McCarthy PM, Albert NM, Lytle BW, Navia J, et al. The impact of left ventricular reconstruction on survival in patients with ischemic cardiomyopathy. Eur J Cardiothorac Surg. 2006;30:753-61.

13. Adams JD, Fedoruk LM, Tache-Leon CA, Peeler BB, Kern JA, Tribble CG, et al. Does preoperative ejection fraction predict operative mortality with left ventricular restoration? Ann Thorac Surg. 2006;82:1715-9.

14. Schreuder JJ, Castiglioni A, Maisano F, Steendijk P, Donelli A, Baan J, et al. Acute decrease of left ventricular mechanical dyssynchrony and improvement of contractile state and energy efficiency after left ventricular restoration. J Thorac Cardiovasc Surg. 2005;129:138-45.

15. Tulner SA, Bax JJ, Bleeker GB, Steendijk P, Klautz RJ, Holman ER, et al. Beneficial hemodynamic and clinical effects of surgical ventricular restoration in patients with ischemic dilated cardiomyopathy. Ann Thorac Surg. 2006;82:1721-7.

16. Yamaguchi A, Adachi H, Kawahito K, Murata S, Ino T. Left ventricular reconstruction benefits patients with dilated ischemic cardiomyopathy. Ann Thorac Surg. 2005;79:456-61.

17. Mickleborough LL, Merchant N, Ivanov J, Rao V, Carson S. Left ventricular reconstruction: early and late results. J Thorac Cardiovasc Surg. 2004;128:27-37.

18. Carabello BA. The changing unnatural history of valvular regurgitation. Ann Thorac Surg. 1992;53:191-9.

19. Vanoverschelde JL, Depre C, Gerber BL, Borgers M, Wijns W, Robert A, et al. Time course of functional recovery after coronary artery bypass graft surgery in patients with chronic left ventricular ischemic dysfunction. Am J Cardiol. 2000; 85:1432-9.

20. Mahrholdt H, Wagner A, Parker M, Regenfus M, Fieno DS, Bonow RO, et al. Relationship of contractile function to transmural extent of infarction in patients with chronic coronary artery disease. J Am Coll Cardiol. 2003;42:505-12.

21. Bellenger NG, Burgess MI, Ray SG, Lahiri A, Coats AJ, Cleland JG, et al. Comparison of left ventricular ejection fraction and volumes in heart failure by echocardiography, radionuclide ventriculography and cardiovascular magnetic resonance; are they interchangeable? Eur Heart J. 2000;21:1387-96.

22. Doenst T, Velazquez EJ, Beyersdorf F, Michler R, Menicanti L, Di Donato M, et al. To STICH or not to STICH: we know the answer, but do we understand the question? J Thorac Cardiovasc Surg. 2005;129:246-9.

23. Buckberg GD. Questions and answers about the STICH trial: A different perspective. J Thorac Cardiovasc Surg. 2005;130:245-9.

24. Takaro T, Hultgren HN, Lipton MJ, Detre KM. The VA cooperative randomized study of surgery for coronary arterial occlusive disease II. Subgroup with significant left main lesions. Circulation. 1976;54:III107-17.

25. Sheldon WC, Loop FD, Proudfit WL. A critique of the VA cooperative study. Cleve Clin Q. 1978;45:225-30.

26. Bursi F, Weston SA, Redfield MM, Jacobsen SJ, Pakhomov S, Nkomo VT, et al. Systolic and diastolic heart failure in the community. JAMA. 2006;296:2209-16.

27. Lehmann C. Economic benefits of e-technology in managing congestive heart failure. 2005. Center for Aging Services Technology (CAST), American Association of Homes and Services for the Aging. Available at: http://www.agingtech. org/documents/CHF_Exec_Summary.pdf. Accessed July 29, 2009. 


\section{Supplemental Data $1 *$}

Initial Evaluation of Patients for Eligibility for Randomization in Specified Stratum

Therefore, a 2-step process is proposed. The first step uses the best available

LV assessment by either a contrast, gated single photon emission computed tomography, or CMR ventriculogram read at the clinical sites or a resting echocardiogram read by the Echo Laboratory. This first step will identify patients meeting LVEF entry criteria and

characterize the extent of anterior LV wall dysfunction needed to evaluate SVR eligibility. After completion of the first step, patients will be approached for informed consent for randomization. The second step to confirm the accuracy of these criteria by CMR or radionuclide LV assessment proceeds only in consenting patients.

\section{Supplemental Data 2}

\section{CABG + SVR Definition}

The two criteria used by the Surgical Therapy Committee to define the acceptable range of specific operative maneuvers essential to be considered an acceptable technical SVR operation for the STICH Trial will be any ventricular reconstruction method that consistently results in (1) a low operative mortality and (2) an average EF [ejection fraction] increase of $10 \%$ and average $\mathbf{L V}$ end-systolic volume index decrease of $30 \%$ as assessed on the 4-month postoperative CMR measurement.

\section{Supplemental Data 3}

\section{B.3. Rationale for Noninvasive Cardiac Imaging Studies}

The common clinical practice of not offering $\mathrm{CABG}$ to patients with $\mathrm{LV}$ dysfunction in regions found to be nonviable on noninvasive studies is not justified by published data.

The STICH Trial proposes to use core laboratories for cardiac magnetic resonance (CMR), echocardiography (ECHO), and radionuclide (RN) studies to insure standardization of testing practices and of data analysis for operational use of these studies in the STICH Trial.

\section{Supplemental Data 4}

Over 3 years, 50 clinical sites will recruit 2800 patients with heart failure, left ventricular ejection fraction less than 0.35 , and CAD [coronary artery disease] amenable to CABG. From http://clinicaltrials.gov/show/NCT00023595.

\footnotetext{
* Unpublished information in the Supplemental Data sections is from the funded STICH grant document, which is "publicly available" through the Freedom of Information Act. (Bold type was added by the authors.)
} 


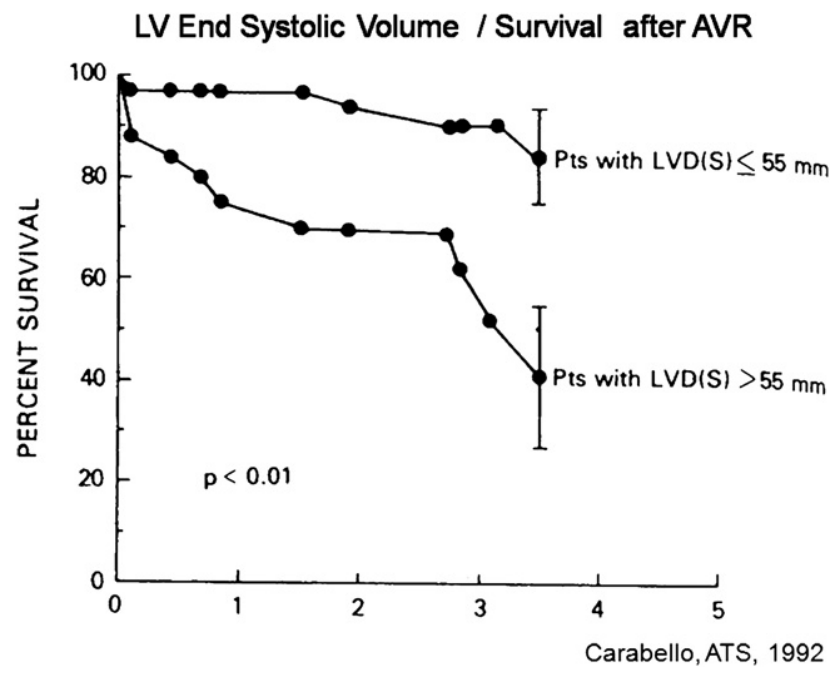

FIGURE E1. Adverse effects on postoperative mortality after aortic valve replacement $(A V R)$ when $\mathrm{LV}$ end-systolic volume dimension exceeds $55 \mathrm{~mm}$. Similar adverse changes were reported after end-systolic volume index exceeded $55 \mathrm{~mL} / \mathrm{m}^{2}{ }^{18} \mathrm{LVD}(\mathrm{S})$, Left ventricular diameter (systolic). Reprinted with permission. ${ }^{18}$

\section{Projected a F Related Costs per Year}

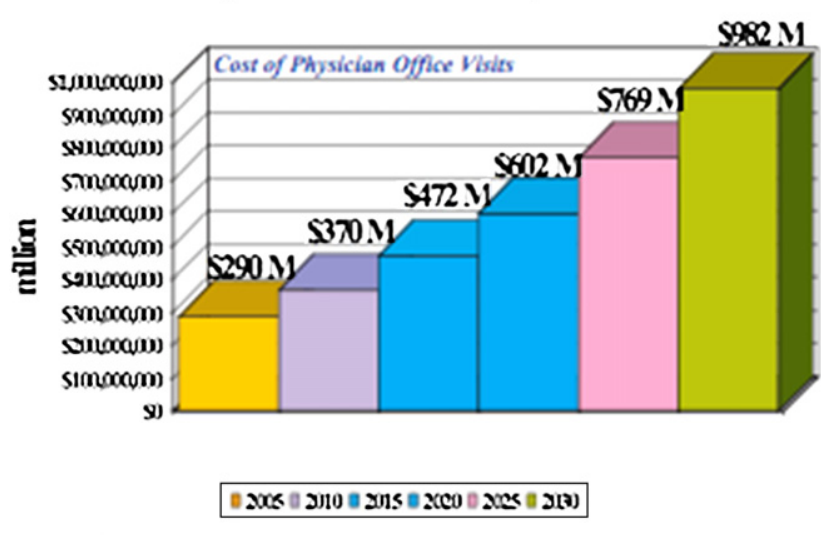

$2030 \sim \$ 1$ trillion / year

FIGURE E2. Time -related cost of health care due to physician visits in the congestive heart failure $(\mathrm{CHF}$ ) population, when costs were estimated during a time intervals between 2005 and 2030. Reprinted with permission. ${ }^{27}$ 